\title{
The Effect of Web2.0 on Learning Management System
}

\author{
Li Chunyan ${ }^{1}$, Cui Haitao ${ }^{2}$ and Li Guolin ${ }^{3}$ \\ ${ }^{1,3}$ Colloge of Education, Hebei Normal University of Science \& Technology \\ Qinhuangdao, Hebei, P.R.China, 066004 \\ ${ }^{2}$ Center for Educational Technology, Qinhuangdao No.1 Senior School \\ Qinhuangdao, Hebei, P.R.China, 066004 \\ ${ }^{1}$ licy6035@126.com, ${ }^{2}$ cuihaitaopaper@163.com, ${ }^{3}$ lglccnu@126.com,
}

\begin{abstract}
\end{abstract}
With the development of online education, online teaching ândonline Teaning are playing an increasingly important role in modern teaching. Learning management system (LMS) is basic environment of developing online learning. It hos offered a network environment of study and work for teachers and students, it is a conservative technolggy for managing group, providing tools, and delivering content. Media coverage of Web 2.0 concentrates on the common applications/services such as blogs video sharing, social networking and podcasting - a more socially connected Web in which peoplevean contribute as much as they can consume.web2.0 created enormous challenges to LMS. According to a literature search and empirical investigation, this stud describes the effect of Web2.0 on LMS. The first is integrating Web 2.0 Features into a Learning Management System, using edu2.0 as an example. The second is using web2.0 applications as an LMS. The main advantages of choosing web2.0 as LMS and a case are showed. At last, it tells us how to choose between the LMS and the web2.0.

Keywords: LMS, learning management system, web2.0

\section{Introduction}

There are many advantages to online and computer-based learning when compared to traditional face-to-face courses and lectures. Students may have the option to select learning materials that meets their level of knowledge and interest, Students can study anywhere they have access to a computer and Internet connection. It is flexible to join discussions in the bulletin board threaded discussion areas at any hour, or visit with classmates and instructors remotely in chat rooms, Instructors and students both report eLearning fosters more interaction among students and instructors than in large lecture courses. E-Learning can accommodate different learning styles and facilitate learning through a variety of activities. A learning management system (LMS) is software used for delivering, tracking and managing education. LMSs range from systems for managing educational records to software for distributing courses over the Internet and offering features for online collaboration. So LMSs are an increasingly important part of online education. When choosing a Course Management System, the usability of the system is the key to the effectiveness and efficiency of the online courses that are to be implemented. Web 2.0 is the popular term for advanced Internet technology and applications including blogs, wikis, RSS and social bookmarking. The two major components of Web 2.0 are the technological advances enabled by Ajax and other new applications such as RSS and Eclipse and the user empowerment that they support. Web 2.0 can create changes in LMSs. 


\section{Understanding of Web2.0 and Learning Management System}

\subsection{Web2.0}

Web 2.0 is term that was introduced in 2004 and refers to the second generation of the World Wide Web. The term "2.0" comes from the software industry, where new versions of software programs are labeled with an incremental version number. Like software, the new generation of the Web includes new features and functionality that was not available in the past. However, Web 2.0 does not refer to a specific version of the Web, but rather a series of technological improvements. Web 2.0 basically refers to the transition from static HTML Web pages to a more dynamic Web that is more organized and is based on serving Web applications to users. Other improved functionality of Web 2.0 includes open communication with an emphasis on Web-based communities of users, and more open sharing of information. Blogs, wikis, and Web services are all seen as components of Web 2.0.Web 20 technologies provide a level user interaction that was not available before [1]. Websites have become much more dynamic and interconnected, producing "online communities" and nhaking it even easier to share information on the Web. While Web 2.0 may be a static label given to the new era of the Web, the actual technology continues to evolve and change.

Web 2.0 offers all users the same freedom to contribute. Web 2.0 websites allow users to do more than just retrieve information. By increasing what was already possible in "Web 1.0", they provide the user with more user-interface, software and storage facilities, all through their browser. Web2.0 provides more opportunity to us to participate in Website Content. Central to Web 2.0 is the requirement for interactive systems to enable the participation of users in users and social interaction Web2.0 emphasizes interactivity. Web 2.0 is much more than just technology. It's a way of thinking, anew perspective on resources constructionfrom recipients of message lo initiative, to release information, Web 2.0 thrives on network effects: people involved with website content, and interact with others. Some examples of features considered to be part of Web 2.0 are listed below:

Blogs - also known as Web 10gs, these allow users to post thoughts and updates about their life on the Web.

Wikis - sites like Wikipedia and others enable users from around the world to add and update online content.

Social networking sites like Facebook and MySpace allow users to build and customize their own profile sand, communicate with friends.

Web applications - a broad range of new applications make it possible for users to run programs directly in a Web browser.

\subsection{Learning Management System}

A learning management system (LMS) is a software application or Web-based technology used to plan, implement, and assess a specific learning process. Typically, a learning management system provides an instructor with a way to create and deliver content, monitor student participation, and assess student performance [2]. A learning management system may also provide students with the ability to use interactive features such as threaded discussions, video conferencing, and discussion forums. The focus of an LMS is to deliver online courses or training to learners, while managing students and keeping track of their progress and performance across all types of training activities. Most LMSs are Web-based, built using a variety of development platforms, like Java/J2EE, Microsoft .NET or PHP. They usually employ the use of a database like MySQL, Microsoft SQL Server or Oracle as backend. Although most of the systems are commercially developed and have commercial 
software licenses there are several systems that have an open-source license. In the relatively new LMS market, commercial vendors for corporate and education applications range from new entrants to those that entered the market in the nineties. In addition to commercial packages, many open source solutions are available. In the higher education market as of fall 2011, Blackboard is the leading provider with 51\% market share, with Moodle (19\%) and Desire2Learn (11\%) being the next two largest providers. usually, A LMS has the following functions:

To manage basic subject administration such as announcements, class lists and group management

To provide online versions of class materials and readings

To offer extended content such as multimedia files

To allow electronic submission of assignments

To download, mark and return assignments and feedback

To conduct online tests and surveys

\section{Integrating Web 2.0 Features into a Learning Management System}

\subsection{Overview}

These past years, a major innovation known as Web 2.0 rose up from information technology. It is a complex concept consisting in new ways of communication between users and web site content control by users. Now, users are newed as the heart of a web site. It redefines our perception of the Web in the way we access, communicate and learn information in our everyday life (Kblbitsch and Maurer, 2006). Blogging, wiki or pod-casting are examples that nobody can't miss. Beside this revolution, e-learning frameworks show some limitations while using it) For instance, students like to discuss about an online course on a real-time chat system. It is useful and it improves their knowledge. Nevertheless, it is useless when a user wants to keep track of the conversation content because it's not possible. Another point lies in the idea that human behavior of group working is not translated into current e-learning systems, or at least not as well as Web 2.0 sites do. Here a few boundaries of E-learning frameworks become visible.

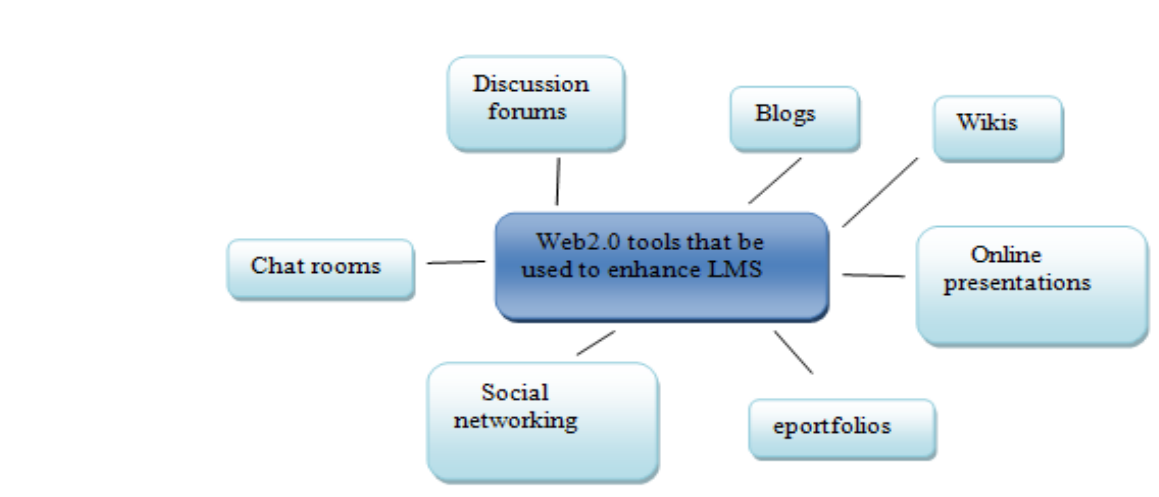

Figure 1. Web2.0 Tools

The e-Learning world is overcrowded by Learning Management Systems. But, lots of them are mere content delivering platforms and only a few provide a good end-user satisfaction. Nowadays, a growing advent called Web 2.0 is gaining ground in various application fields, in the meanwhile, most of features that could be qualified as Web 2.0 compliant could easily 
be shaped into learning management systems and be a way to overcome their current limits. Web 2.0 tools benefit students by engaging them with your content in interesting ways and creating online communities. For instance, users of these future integrated systems would be attracted not only to study a course, but also because they can communicate with other users in a collaborative way and learn from each other. There are many web2.0 applications that can be used in LMS. See figuer1. Integrated Web 2.0 functionality within these systems can increase collaboration and participation [3]. By implementing Web 2.0 tools within an LMS, schools can give their students access to on-demand learning materials and facilitate a space for collaboration with students.

\subsection{Example}

The LMS is the University's online system for delivering subject content to students. Our LMS uses educational technologies from various enterprise proyiders such as BlackBoard, TurnItIn and Learning Objects to Open-source software such as Moodle, saklai, Claroline and so on. With the rapidly increasing popularity of the intermet in recent years, the LMS based on cloud computing and Internet hosting is more and more popular All kinds of LMSs serve a similar function. We take edu2.0 as an example.

edu2.0 (http://www.edu20.org) is a simple, powerful e-learning platform with nothing to download or install. It includes a comprehensive set of LMS features as well as Facebook-like news feeds and social networking [4]. We provide a wide variety of integrated options for collaboration, including groups, forums, chat rooms, wikis, blogs, and video conferencing. See figure2.Our support for groups is particularly strong, with news and activity feeds for each group as well as its own sêt of collaboration tools. By default, a list of all the groups that a user is a member of is displayed in the lef column of every page. This site supports personal blogs, class blogs and groups' blogs.

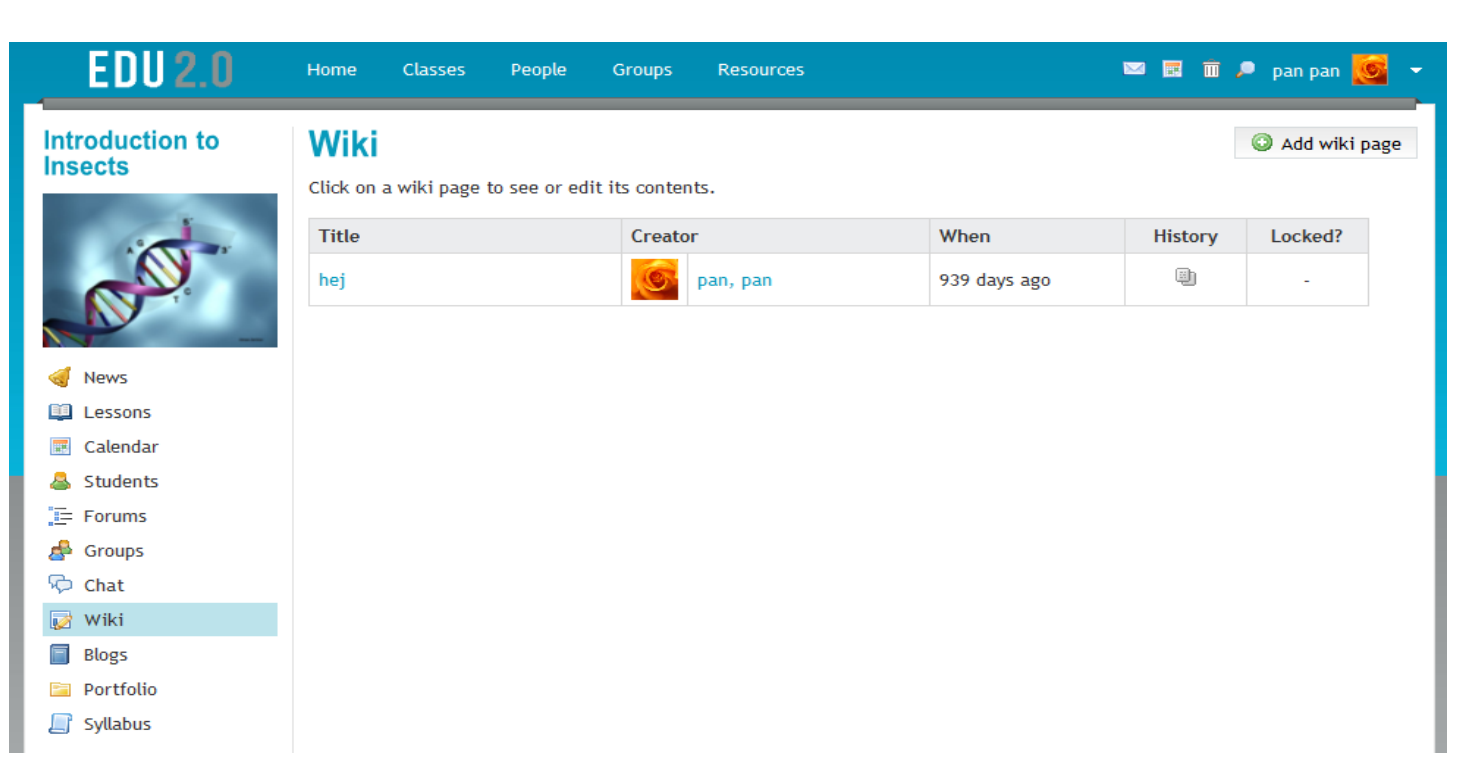

Figure 2. Web2.0 Tools of the Platform

Web2.0 carries out the thinking of "user-centered", LMS borrows it, each user has home page which provides an convenient overview of many aspects of your account, including a feed that aggregates the main contents of your class feeds, group feeds, announcements, today's events, upcoming events and your to-do list. Take edu2.0 as an example, students can 
instantly see links to all assignments that are due, class announcements, school announcements, and other important news. See Figure 3. Similarly, teachers can see links to all the assignments the need grading, school announcements, and postings from their friends and colleagues. You can also add custom content boxes to home pages that only appear for specified account types. For example, you could upload a welcome video that is only visible to parents, or special instructions that are only visible to students.

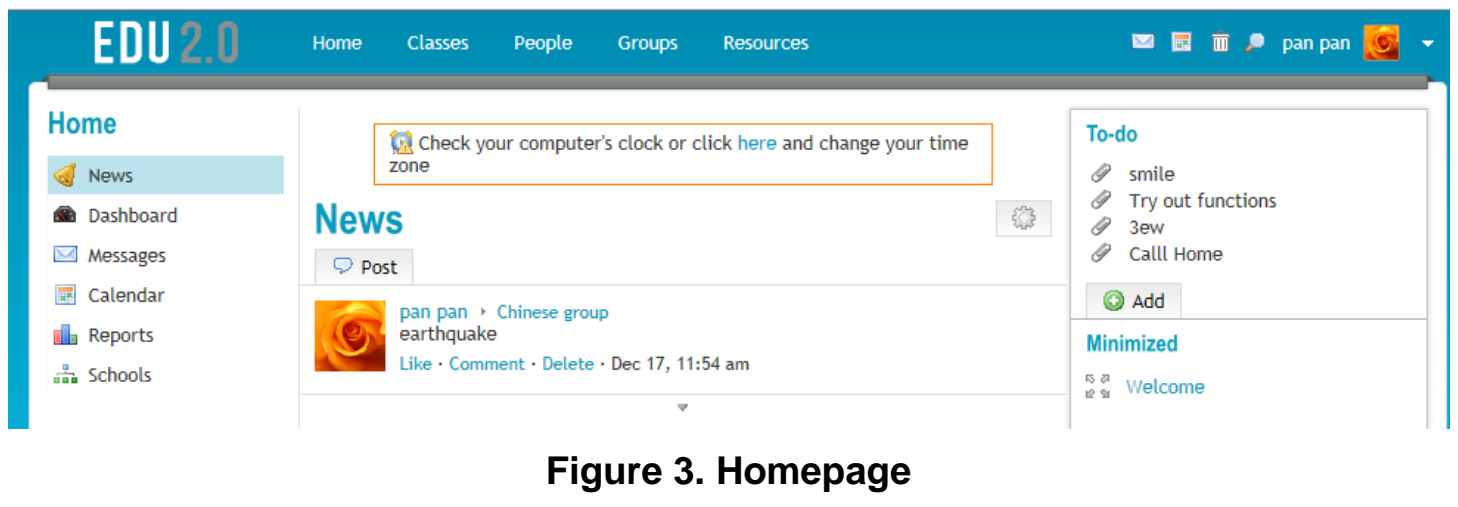

There are many places in the site where youcan upload resources. For example, each class has a 'resources' area where teachers caf share resouces with the students. Similarly, each group has a 'resources' area where members can share resources with other members, each section of a lesson has a 'resøurces area, and each user gets a 'locker' for their private resources. A locker is a place where you cantupload and view private resources. Resources can be organized into foldersfor convenience. To view your private resources or upload new ones, click Resources/Locker.

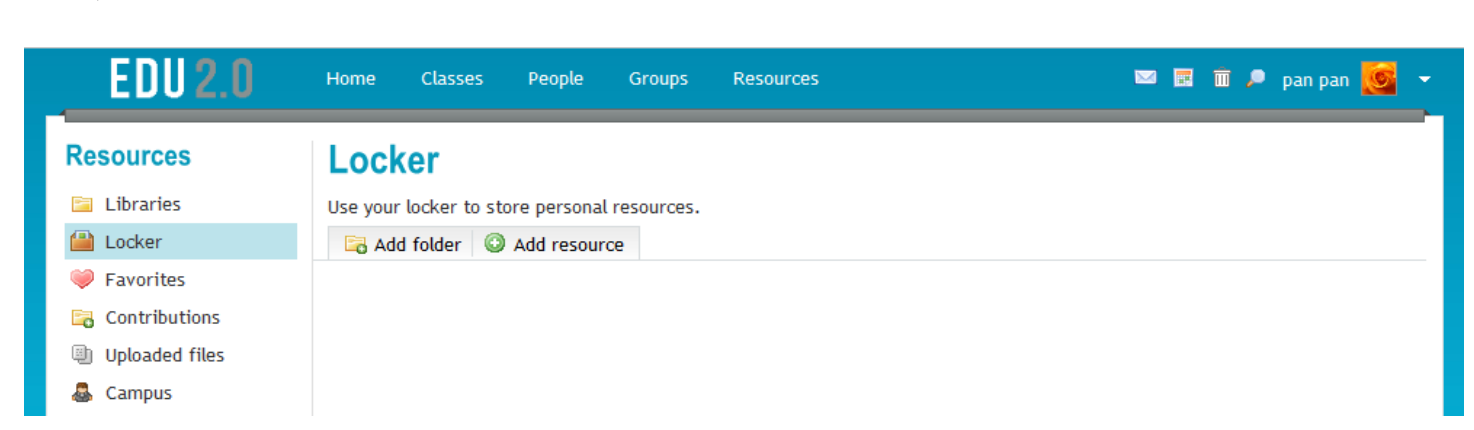

Figure 4. Resources of the Platform

\subsection{Analysis}

A growing advent called Web 2.0 is gaining ground in various application fields. Briefly speaking, Web 2.0 is about content management and new ways of communication and interaction between users. Currently, this technology is more and more viewed by scientists as a new way of learning. As a consequence, this trend directly competes with e-learning systems. But in the meanwhile, most of features that could be qualified as Web 2.0 compliant could easily be shaped into learning management systems and be a way to overcome their current limits. For instance, users of these future integrated systems would be attracted not only to study a course, but also because they can communicate with other users in a collaborative way and learn from each other. 
Social learning is based on the premise that our understanding of content is socially constructed through conversations about that content and through grounded interactions, especially with others, around problems or actions. The focus is not so much on what we are learning but on how we are learning .Constructivism states that Learning is a social activity, and our learning is intimately associated with our connection with other human beings, our teachers, our peers, our family as well as casual acquaintances, including the people before us or next to us at the exhibit. Web2.0 emphasizes the idea that it is important to improve the participation of users, the idea is consistent with Constructivist Learning Theory. nowadays, LMSs provided facilitation for the theory of "taking learner as the centre" and" stimulating students' participation" with home page, blog, wiki, social networking. But it is iniportant to point out that, the key of individual's initiative is educational design, teaching activities design and organization, web2.0 provided a platform for students learning.

\section{Choosing Web2.0 as Learning Management System}

\subsection{Overview}

While the LMS has become central to the business of colleges and universities, it has also become a symbol of the higher learning status quo. Manystudents, teachers, instructional technologists, and administrators consider th DMS too inflexible and are turning to the web for tools that support their everyday contmunication, prodúctivity, and collaboration needs. Blogs, wikis, social networking sites, microbloggting tools, and other web-based applications are supplanting the teaching and Teafining tools previously found only inside the LMS [5]. In order to remedy the limitations of the LMS, a new educational concept called Personal Learning Environment (PLE) has been actively researched to be extended from the institutional learning environment.PLE provides the essential quality for both educators and learners to be able to communicate, collaborate, create and search for knowledge and connect with one another where this relationship may not end as the semester ends.

There is growing awareness $\mathrm{Mr}$ higher education of student levels of engagement in web2.0 environment, in contrast to their engagement in learning management systems (LMSs) hosted by their institutions. Social networking sites, blogs, and wikis offer students unprecedented opportunities to create and share content and to interact with others. These sites are used regularly by the majority of students and provide possibilities for customization and a sense of ownership currently impossible in LMSs.

Schools can úse various web2.0 environments, which are easily available online and could be implemented with minimal software cost, for the purpose of teaching and learning. Web2.0 environmen have the potential to facilitate students' engagement for independent and collaborative learning, enhance student-teacher interactions, and develop students' technological skills. A framework is constructed to facilitate the conceptualization of the various pedagogical approaches for learning using such web2.0 environment - learning from and with technology is proposed. Learning from technology leans itself more towards the didactic and behaviouristic theories whereas learning with technology has its origin from the constructivism and social constructivism paradigms. In addition, both the didactic and constructivist pedagogical approaches are applicable for online learning as they could be used to achieve different outcomes depending on the learning objectives. Implicit in the findings is also the importance of the teachers' commitment and competencies and good infrastructural and technical support in the use of technologies for teaching and learning in an educational setting. 


\subsection{Why Choosing Web2.0 as LMS}

What considerations support the decision to either augment or replace an institution's existing learning management system (LMS) with a cloud-based, Web 2.0 technology tool to support students' learning?

An LMS should be treated as a pedagogical tool and Lane notes that many faculty members fail to realize LMSs are based on a set of pedagogical principles. Someone suggests that LMSs are relatively inflexible systems, with the standard organizational unit being the "course"-a term inappropriate for the hierarchy of faculties, departments, subject areas, programs, courses, modules, and other organizational concepts found in educational institutions. Most current systems are formulated around a traditional view of teaching, whith a focus on the instructor as a course manager and deliverer of instruction. An argument is increasingly being voiced that institution should no longer try to provide online learning facilities for their students and should instead tap into free resources on-the internet [6]. It is possible to create meaningful, authentic learning experiences for students within the boundaries of your available LMS, but in some cases, authentic instructional activities require looking outside the LMS.

A LMS is an application that provides a comprehensive set of tools for educators to manage learning resources, administrative functions, assessments, and grading. Some educators argue that because of evolving Web 2.0 applications, students can be better served by Web2.0, a toolbox of web resources that might include social bookmarking tools, document sharing applications, social networking sites, timeline tools, and media options available in the cloud. Underlying th 18 approach is the belief that these skills will be useful in the workplace. It is necessary asing the tools they will encounter in their professional lives. For example, students who will be working m $\mathrm{K}-12$ school contexts are not likely to work with a major commercial LAIS and withaye to rely on tools freely available on the web (such as PBWorks or ViceThread). Beeause new and interesting web-based tools with relevance to our programs emerge outside the LMS, working outside the LMS is necessary to keep our students cognizant of current trends. Our students' learning activities outside the LMS allow them to work on projects using tools they will be using after graduation (realworld relevance) [7]. We realide that online learning will be part of the future personal and work lives of most of our students, so we choose web2.0 which is relevance to future personal and work lives.

Another reason/of using web2.0 is that students should become more familiar with today's technology tools. Churches suggest that utilization of new technology tools goes beyond the cognitive doman focus of the original taxonomy, emphasizing the synergy between cognition and technology tools. With the development of the network technology, the number of Internet users continues to increase. The application and popularity of blog, wiki, social networking has already become an important part of students life. Most students are familiar with web2.0 applications.

\subsection{Example}

Richard decides to use a blogging tool to create his course materials on the open web. His first step is to set up a blog where students can find course content. A table of content lists each class session by title and offers a link to the materials on that topic. Individual blog pages for class modules include text, images, embedded YouTube videos, voicethreads, data visualizations, or presentations. They also contain links to resources for further study.

As students visit the blog before each class session, they are encouraged to use embedded google forms to offer feedback. Their comments let teacher know what he needs to clarify 
when the class meet .periodically, students assess their knowledge of a topic with a test created in studymate. This helps them identify areas where their own understanding is incomplete in time for them to ask questions during the subsequent class session

Later in the course, students work in learning teams, writing group papers using Google docs. As each group of students completes their paper, they post it to a team blog page they are required to read the papers of all other teams and post a paragraph in comment. Teams can then modify their papers for final presentation, which teacher can review in Google Docs. There he can check the revision history to see which team members wrote which parts. At that point because the blog tool has no gradebook feature, teacher enters the grades for these team assignments in an open source courseware tool that is integrated with the student information system [8].

\subsection{Advantage}

PLE is introduced due to the disadvantages of LMS learning model which may not be sufficient to accommodate learners' needs today that are 'more socially and connectedly demanding. The idea for PLE was built upon the isualization of "The VLE of the future", who believes that the VLE should not be institutional but personal to support both formal and informal learning needs of a learner today. The objective of RLE is to give learners autonomy in learning, where learners are free to choose the learning methods and tools based on their preference in constructing new knowledge, hence taking control of their own learning process, adapting more of the learning theory of humanism. The theory of humanism stress on learning is student centered and personalized. Holistic perspective combines experience, perception, cognition and behavion. We could conclude that using Web 2.0 applications at online learning has been a very positive expertence. The main advantages of this change are the following:

A. more collaborative work

Lack of communication can be broken easily with social software: prompting students to comment their opinions in blogs following each other in microblogging networks or using them to interact with teachers. Web 2.0 is more than just adding technology to education. Teachers have to combine misdellaneous sources and keep their students on the dance floor. Content can be self-made yemixed using someone else's material, or even created by the students themselves [9].

B .Personal Learning Environments
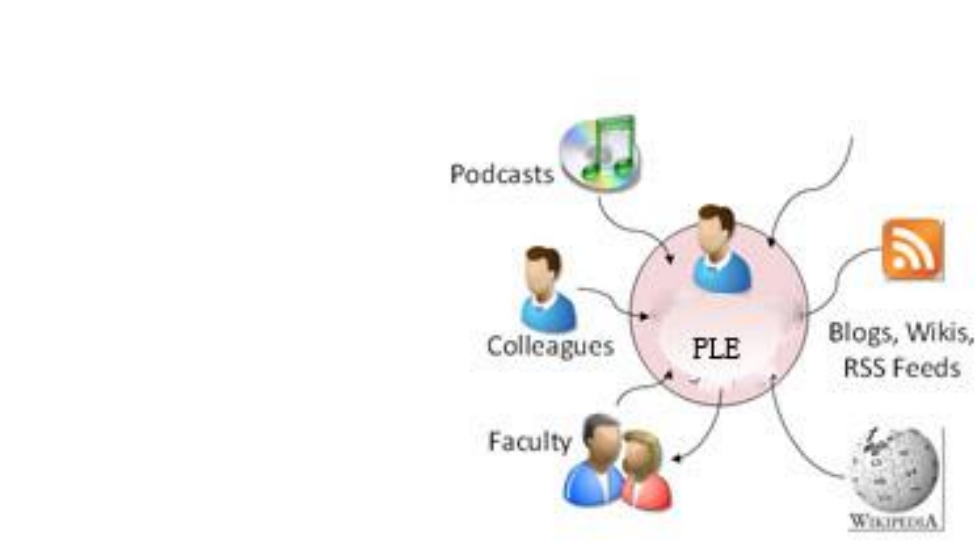

Figure 5. Database of the Platform 
Instead of working with just a sole information source, several diverse resources are used: blogs for group work, microblogs for communication, RSS feeds, multimedia clips linked from a wide range of platforms (e.g. Youtube, Flickr, SlideShare) and a wiki to gather them all in a common place and support collaborative work. Personal blogs or tumblelogs are used as virtual portfolios. To store all subject-related resources created by teachers, students or any other online content service provider. Students can organize this Personal Learning Environments (PLE) freely, without being evaluated [10].

"Web 2.0" refers to a second generation of web-based communities and online services, such as social-networking sites, wikis, and social indexing sites, which enable creativity, collaboration and sharing between users. With the rapid development of "Web 2.0 " network education is changing a lot. In contrast to traditional LMS-driven VLE solutions, PLE based on web2.0 takes a more natural and learner-centric approach and is characterized by the freeform use of a set of lightweight services and tools that belong to and are controlled by individual learners. PLEs based on Web2.0 tools consist/of three parts. They are knowledge digging, knowledge coding and knowledge shifting. So PLEs, are not an application but rather a new approach to the use of new technologies for learning.

\section{Comparison of LMS and web2.0 as EMS}

Some schools have the capability to developing LMS themselves, such as Elaborate Courses in some universities, the independent development can correspond to actual needs, but it need a great deal of time, resource and money, so only very few universities can do it, and very few teachers can use the S S f developed LMS. Some schools purchase commercial software, for example Blackboard The advantage is that it is powerful, but the disadvantage is that the price is too high. So only very few universities can buy commercial software, and very few teachers can use commercial software. The "free" nature of web-based applications is a double-edged sword. Although not cbarged to use them, institutions and individual users have very little leverage with application providers when performance degrades, applications crash, or data is exposed or lost. Both thethods have their advantages and disadvantages [11].

\begin{tabular}{|l|l|}
\hline \multicolumn{1}{|c|}{ LMS Strengths } & \multicolumn{1}{|c|}{ LMS Weaknesses } \\
\hline Simple, consistenf, and structured & $\begin{array}{l}\text { As widely implemented, time-bound (courses } \\
\text { disappear at the end of the semester) }\end{array}$ \\
\hline $\begin{array}{l}\text { Integration with student information } \\
\text { systems (\$ISs), with student rosters } \\
\text { automatically populated in courses }\end{array}$ & Teacher, rather than student, centric \\
\hline Private and secure (FERPA compliant) & $\begin{array}{l}\text { Courses walled off from each other and from } \\
\text { the wider web, negating the potential of the } \\
\text { network effect }\end{array}$ \\
\hline $\begin{array}{l}\text { Simple and inexpensive to train and } \\
\text { support (compared to supporting multiple } \\
\text { tools) }\end{array}$ & $\begin{array}{l}\text { Limited opportunities for students to "own" } \\
\text { and manage their learning experiences within } \\
\text { and across courses }\end{array}$ \\
\hline
\end{tabular}




\begin{tabular}{|c|c|}
\hline $\begin{array}{l}\text { Tight tool integration (such as quiz scores } \\
\text { populated in gradebooks) }\end{array}$ & Rigid, non-modular tools \\
\hline $\begin{array}{l}\text { Supports sophisticated content structuring } \\
\text { (sequencing, branching, adaptive release) }\end{array}$ & Interoperability challenges and difficulties 26 \\
\hline PLE Strengths & PLE Weaknesses \\
\hline $\begin{array}{l}\text { Almost limitless variety and functionality } \\
\text { of tools, customizable and adaptable in } \\
\text { multiple configurations and variations }\end{array}$ & $\begin{array}{l}\text { Complex and difficult to create for } \\
\text { inexperienced students and faculty mémbers }\end{array}$ \\
\hline $\begin{array}{l}\text { Inexpensive - often composed of free } \\
\text { and open source tools }\end{array}$ & $\begin{array}{l}\text { Potential security and data exposure problems } \\
\text { (FERPA issues abound) }\end{array}$ \\
\hline $\begin{array}{l}\text { No artificial time boundaries: remains } \\
\text { "on" before, during, and after } \\
\text { matriculation }\end{array}$ & Limited institutional controloyer data \\
\hline $\begin{array}{l}\text { Open to interaction, sharing, and } \\
\text { connection without regard to official } \\
\text { registration in programs or courses or } \\
\text { particular institutions }\end{array}$ & $\begin{array}{l}\text { Absent or unenfórceable service-level } \\
\text { agreements; no ability to predict or resolve } \\
\text { web applicâtionperformance issues, outages, } \\
\text { or even disappearance }\end{array}$ \\
\hline $\begin{array}{l}\text { Student-centric (each student selects and } \\
\text { uses the tools that make sense for their } \\
\text { particular needs and circumstancels) }\end{array}$ & $\begin{array}{l}\text { Lacks centrally managed and aggregated } \\
\text { group rosters (such as class rolls) }\end{array}$ \\
\hline $\begin{array}{l}\text { Learning content and conversations are } \\
\text { compilable via simple techfologies like } \\
\text { RSS }\end{array}$ & $\begin{array}{l}\text { Difficult and potentially expensive to provide } \\
\text { support for multiple tools and their } \\
\text { integrations with each other and with } \\
\text { institutional systems }\end{array}$ \\
\hline
\end{tabular}

The e-Learning world is overcrowded by Learning Management Systems. Whatever they are Web- based or stand-alone software, lots of them are mere content delivering platforms and only a few provide a good end-user satisfaction. It is possible to create meaningful, authentic learning experiences for students within the boundaries of your available LMS, but in some cases, authentic instructional activities require looking outside the LMS. An LMS should be treated as a pedagogical tool, many teachers fail to realize LMSs are based on a set of pedagogical principles. Most current systems are formulated around a traditional view of teaching, with a focus on the instructor as a course manager and deliverer of instruction. Teachers need to look beyond those functions and question whether or not the LMS fosters a collaborative, constructive, shared pedagogy of authentic learning. While LMSs continually add tools to provide additional functionality, they typically lag behind the tools available in the Web 2.0 world. The most compelling argument for the use of Web 2.0 tools may be that it is simply unnecessary to pay for additional modules/functions within an LMS when tools that serve learning objectives well are free and widely available. To accommodate a "pedagogy comes first" philosophy, instructors should not feel limited by the set of tools contained within an LMS.

The success of PLE implementation is highly depended on learners' competency and skillfulness in using Web 2.0 technology, their preferences in the learning process, and their ability to become autonomous. Hence, before a design of PLE is proposed, gathering data on 
learners' competency and skill level in using Web 2.0 applications and their learning preferences in the learning process is both essential and informative. Analysis on what majority learners prefer in learning ensures the design of proposed PLE is acceptable to most learners. The findings have shown useful information about the relationship between what the learners are capable of and what the learners choose to use. It is found most learners still choose the traditional way of learning instead of embracing new technology despite their self assessment to be competent and skillful in using Web 2.0 applications. One of the possible reasons for such findings is that both learners and educators are hesitant to explore new techniques in the teaching and learning process due to lack of awareness of such technology that can be used. Another possible reason is learners are less confident in using technology in the learning system where assessment using this technology is still undefined Scaffolding from the educator is found to be still essential to most learners in the learning process where most learners prefer to have clear learning instruction from the educator to achieve the learning goals. The idea of PLE and learner autonomy is still hew to many learners and it is expected to take some time before the idea is fully adopted and practiced anong learners. The implemented prototype is the initial step to introduce the idea and benefits for practicing PLE in the learning process. Although the implemented PLE ls practiced in the context of informal learning, the idea of similar approach can be extended into formal learning which is not focused in this research. More iterations for improvement is required before the design and development of PLE to encourage learner autonomy can yield its ultimate purpose of improving learning experience and promoting lifelon learning among the learners. It is of utmost importance that the success of PLE depends highly on learners' adoption and willingness to actively participate socially using various Web 2.0 applications. Educator plays an important role as facilitator and motivator, who promotes the use of Web 2.0 applications and provides essential scaffolding to the learners in the learning process.

LMSs and Web2.0 as WMIS have thein advantages and disadvantages. This decision was based primarily on schools, students teaching objectives, Teaching content and so on, If we say informational technology were a magic stick, vocational teachers would be magicians using it. The key of online learning is educational design, teaching activities design and organization, whether LMS oryeb2.0 as LMS, is a platform for online learning.

\section{Acknowledgements}

This work was financially supported by the Department of Science and Technology in Hebei province/(13K56206D).

\section{References}

[1] P. Anderson, "What is Web 2.0? Ideas, technologies and implications for education", JISC Technology and Standards Watch, (2007) February.

[2] Wikipedia, http://en.wikipedia.org/wiki/Learning_management_system.

[3] J. L. del Val, A. Campos and P. Garaizar, "LMS and Web 2.0 Tools for e-Learning: University of Deusto's Experience Taking Advantage of Both. Education Engineering (EDUCON)", (2010) April.

[4] http://www.edu20.org.

[5] C. Hodges and J. Repman, "Moving Outside the LMS: Matching Web 2.0 Tools to Instructional Purpose", EDUCAUSE Learning Initiative (ELI), (2011) September.

[6] S. Tyagi, "Adoption of Web 2.0 technology in higher education: A case study of universities in National Capital Region, India. International Journal of Education and Development using Information and Communication Technology (IJEDICT)", vol. 8, no. 2, (2012), pp. 28-43.

[7] N. Sclater, "wen2.0.personal learning environments, and the future of learning management systems.8educase center for applied research", (2008) June.

[8] 7 Things you should know about LMS alternatives, EDUCAUSE Learning Initiative (ELI), (2010) July. 
[9] A. Soumplis, E. Koulocheri, N. Kostaras, N. Karousos and M. Xenos, "Learning Management Systems and Learning 2.0. International Journal of Web-Based Learning and Teaching Technologies (IJWLTT), vol. 6, no. 4, (2011), pp. 1-18.

[10] M. Doktor and M. A. Chatti, "DISCUSSION OF A WEB 2.0 BASED INTEGRATED E-LEARNING AND KNOWLEDGE MANAGEMENT CONCEPT", IADIS International Conference e-Learning (2009).

[11] J. Mot, "Envisioning the Post-LMS Era: The Open Learning Network", EDUCAUSE Quarterly, (2010) March.

[12] Salimah, Mokhtar, Lim and S. Huoy, "Design of Personal Learning Environment Framework for Learner Autonomy", 4th International Conference on Computer Science and Information Technology (ICCSIT'2013), (2013) October 6-7, Dubai.

[13] H. Zhao, L. Yang and Y. Wang, "The personal learning environment (PLE) based on web2.0. Web Society (SWS)”, 2010 IEEE 2nd Symposium on, (2010) August.

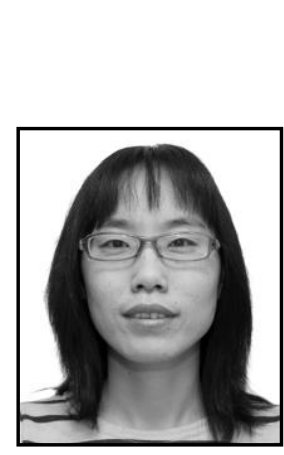

\section{Authors}

Li Chunyan, She received hen bachelor's degxee of science in Northeast Normal University, Changchun, Jilin. (2003) and master's degree of education in Northeast Normal University (2005), Now she is a lecturer in Hebei Normal University of Science \& Technology, Qinhuangdao, Hebei. Her major fields of study are Instructional technology, and distance education.

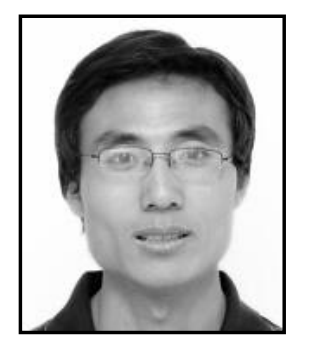

Cui Haitao, He received his bachelor's degree of science in Northeast Normal Eniversity, Changchun, Jilin. (2003). Now he is a teacher in Qinhuangdao No.1,Senior School, Qinhuangdao, Hebei. His major fields of study are instructional design, media teaching theory and distance education.

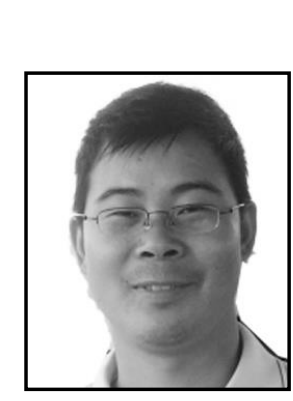

\section{8}
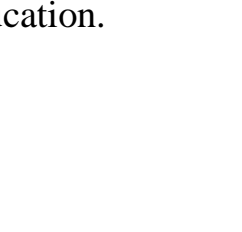

'Li Guolin, He received his bachelor's degree of education technology in Central China Normal University, Wuhan, Hubei (2003). and master's degree of Engineering in Beijing University of Technology, Beijing (2009), Now he is a lecturer in Hebei Normal University of Science \& Technology, Qinhuangdao, Hebei. His major fields of study are instruction design, distance education and construction of digital teaching resources. 